\title{
Mimicking pulmonary multiple metastatic tumors: A case of primary nodular parenchymal pulmonary amyloidosis with review of the literature
}

\author{
LI-NA ZHANG，XIN-YING XUE, NA WANG and JIAN-XIN WANG \\ Department of Respiratory Diseases, Chinese PLA General Hospital, Beijing 100853, P.R. China
}

Received June 21, 2012; Accepted September 12, 2012

DOI: $10.3892 / \mathrm{ol} .2012 .923$

\begin{abstract}
Primary pulmonary amyloidosis is a relatively rare condition, characterized by amyloid deposition in the lungs and other associated structures. We report a case of primary nodular parenchymal pulmonary amyloidosis in a 44-year-old male. The patient was referred to our hospital for further evaluation of multiple lobulated nodules in both lungs. As the multiple lung nodules were suspected to be metastatic, ${ }^{18} \mathrm{~F}$-fluorodeoxyglucose (FDG) positron emission tomography/computed tomography (PET/CT) was conducted, which revealed that the nodules had a mild uptake of ${ }^{18} \mathrm{~F}$-FCG. Amyloidosis was confirmed by conducting a percutaneous CT-guided fine-needle aspiration (FNA) biopsy in the left lung nodule. A literature review of previous studies on primary nodular parenchymal pulmonary amyloidosis from Medline (1970-October 2011) and Embase (1989-October 2011) was also included. Despite its rarity, primary nodular parenchymal pulmonary amyloidosis with a pattern of multiple nodules also forms part of the differential diagnosis of pulmonary metastases with high ${ }^{18} \mathrm{~F}-\mathrm{FDG}$ uptake on PET/CT.
\end{abstract}

\section{Introduction}

Amyloidosis is a clinical disorder caused by extracellular deposition of insoluble abnormal fibrils in various organs and is derived from the aggregation of misfolded, normally soluble, proteins (1). Primary pulmonary amyloidosis is a relatively rare pattern of amyloidosis that is confined to the lungs and associated structures without any other organ involvement. It occurs in 3 patterns: tracheobronchial, diffuse interstitial and nodular parenchymal (2). Radiographically, the lesions of primary nodular parenchymal pulmonary

Correspondence to: Dr Jian-Xin Wang, Department of Respiratory Diseases, Chinese PLA General Hospital, 28 Fuxing Road, Beijing 100853, P.R. China

E-mail: jianxinwang301@yahoo.com.cn

Key words: amyloidosis, pulmonary nodules, metastases amyloidosis may be single or multiple, and are able to calcify or cavitate. It is usually considered in the differential diagnosis of pulmonary primary or metastatic neoplasms. In the present study, we report a case of primary nodular parenchymal pulmonary amyloidosis and review the literature for related cases in Medline (1970-October 2011) and Embase (1989-October 2011).

\section{Patient and methods}

Case report. A 44-year-old male was referred to our hospital for further evaluation of multiple lobulated nodules of varying sizes in both lungs that were detected on a chest computed tomography (CT) scan conducted in a health examination 1 week earlier. The patient's medical history included an appendectomy that was conducted 10 years previously. Additionally, the patient was a non-smoker and did not suffer from pulmonary or systemic symptoms. Physical examinations and laboratory findings, including analysis of tumour markers, were all of no significance. As metastases was suspected in the multiple lung nodules, ${ }^{18} \mathrm{~F}$-fluorodeoxyglucose (FDG) positron emission tomography (PET) /CT was conducted to characterize the nodules and to detect a possible primary malignancy. The ${ }^{18} \mathrm{~F}-\mathrm{FDG}$ $\mathrm{PET} / \mathrm{CT}$ revealed that the nodules had a mild uptake of ${ }^{18}$ F-FDG suggestive of malignancy, with a maximum standardized uptake value (SUVmax) of 1.19 (Fig. 1). Other than these pulmonary nodules, there was no evidence of a high-uptake lesion indicative of a primary malignancy anywhere else in the body. A percutaneous CT-guided fine-needle aspiration (FNA) biopsy was conducted in the left lung nodule. Histologically, the specimens contained amorphous, homogeneous material with a few lymphocytes. Congo red staining was positive (Fig. 2), which confirmed the deposition of amyloid within the specimen. Therefore, we established a diagnosis of primary nodular parenchymal pulmonary amyloidosis and discharged the patient without chemotherapy. The patient enjoys good clinical condition 1 year later.

Methods. We searched for previous cases of primary nodular parenchymal pulmonary amyloidosis in Medline (1970-October 2011) and Embase (1989-October 2011), using 
a search strategy combining medical subject headings and the key words 'lung' and 'amyloidosis'.

\section{Results}

We identified 19 articles (3-21) describing primary nodular parenchymal pulmonary amyloidosis in Medline and Embase. Data on clinical presentation, radiographic pattern, biopsy and survival of 58 patients (including our case) are summarized in Table I. Ages ranged from 44 to 89 years and, consistent with previous findings, the average age of the patients was in the sixth decade $(9,12,16)$. There were 8 male and 12 female cases, while the gender was not indicated in 38 cases. The patients were usually asymptomatic, and the amyloidosis was discovered accidentally on routine chest radiography. Few of these cases were associated with cough or hemoptysis. Radiologically, the nodular parenchymal pattern appeared as solitary or multinodular infiltrates in any lobe, usually mimicking neoplastic growth. Nodules ranged in diameter from 1 to $4 \mathrm{~cm}$, with $15 \mathrm{~cm}$ being the largest nodule reported in the literature (22). Biopsy data were available for 22 patients. Of these 22 patients, nodule resection was conducted in 9 , lobectomy was conducted in 8 , and percutaneous FNA biopsy was conducted in 5. Patients with a nodular parenchymal pattern were all in good condition during follow-up.

\section{Discussion}

Amyloidosis is a disease caused by extracellular amyloid deposits (23). Amyloid fibres are formed by the folding of various fibril precursor proteins into an alternative conformation rich in $\beta$-sheet structures. This characteristic structure results in specific staining with Congo red dye that yields an apple-green birefringence under polarized light microscopy. The genetic and/or environmental factors in individual susceptibility to amyloid deposition have not been elucidated (22). Primary pulmonary amyloidosis is characterized by amyloid deposition in the lungs and other associated structures. Radiologically, the primary nodular parenchymal pulmonary amyloidosis appear as single or multiple nodules in any lobe, and should be considered in the differential diagnosis of pulmonary primary or metastatic neoplasms. In our study, there is no specific examination for the preoperative diagnosis of primary nodular parenchymal pulmonary amyloidosis without the presence of classic clinical findings, laboratory tests and radiological results. The final diagnosis usually requires histological confirmation.

The optimal technique for biopsy is uncertain. In our study, open lung biopsy was the most commonly used method for obtaining biopsy material, but it was more invasive than CT-guided percutaneous FNA biopsy. It is worth noting that CT-guided percutaneous FNA biopsy has also been used when a less invasive approach is necessary and 5 cases of our study were diagnosed solely on the basis of material obtained by percutaneous FNA biopsy, avoiding unnecessary invasive surgical resection. Once the diagnosis is clear, nodular parenchymal amyloidosis rarely requires treatment, which may involve surgical resection if a large nodule causes a space-occupying effect. Additionally, the majority of patients
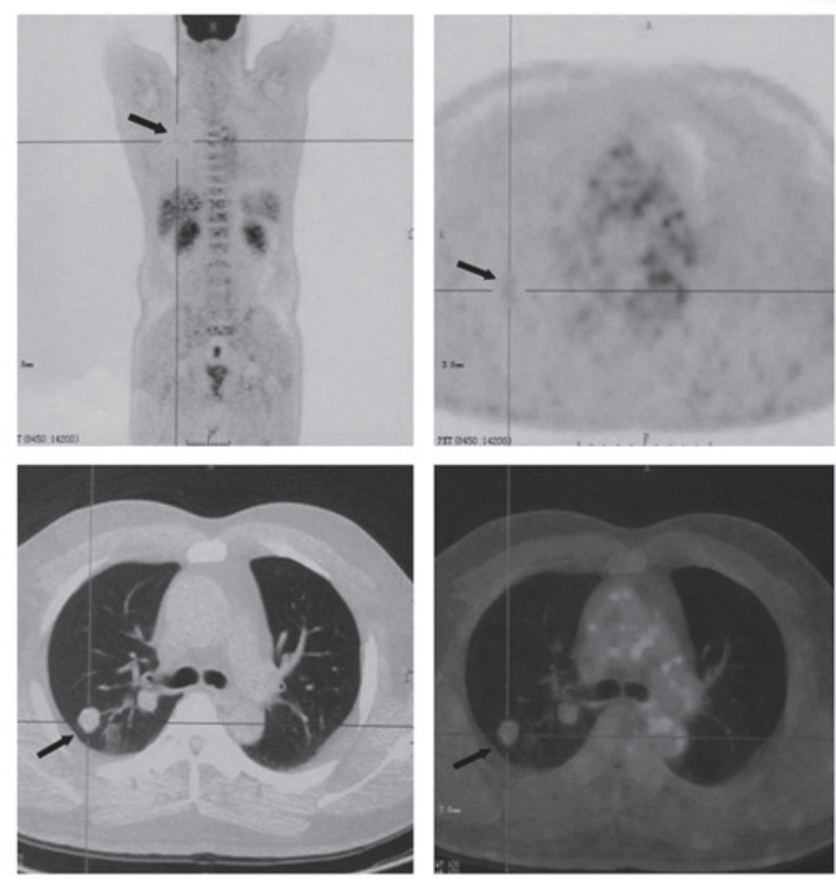

Figure $1 .{ }^{18} \mathrm{~F}$-FDG PET/CT of the present case showing multiple lung nodules with mild ${ }^{18} \mathrm{~F}$-FDG uptake and a SUVmax of 1.19 for a nodule in the right lower lobe (arrow). ${ }^{18} \mathrm{~F}$-FDG PET/CT, ${ }^{18} \mathrm{~F}$-fluorodeoxyglucose positron emission tomography/computed tomography; SUV, standardized uptake value.

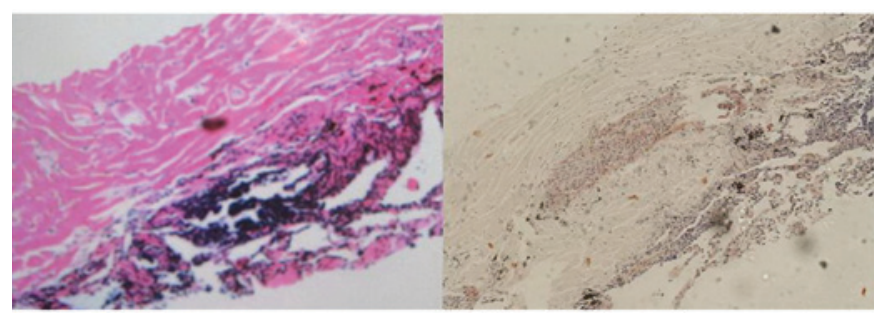

Figure 2. Histology of the present case showing the deposition of amyloid within the nodule. (left, H\&E staining; right, Congo red staining; magnification, $\mathrm{x} 100)$. H\&E, hematoxylin and eosin.

with a nodular parenchymal pattern were in good condition during follow-up.

${ }^{18} \mathrm{~F}-\mathrm{FDG}$ PET/CT is most widely used for cancer detection by revealing which tissues have a high metabolic rate and take up greater amounts of glucose in comparison to the surrounding tissues. To a certain extent, the high metabolic rate usually correlates with more aggressive tumors and a greater number of viable tumor cells (24). The use of ${ }^{18} \mathrm{~F}-\mathrm{FDG}$ $\mathrm{PET} / \mathrm{CT}$ for the diagnostic workup of pulmonary nodules to reduce inappropriate invasive diagnostic investigation and subsequent complications is emerging. Duhaylongsod et al (25) reported that the SUV of ${ }^{18} \mathrm{~F}-\mathrm{FDG}$ uptake in malignant nodules ( $\mathrm{SUV} \geq 2.5$ ) was greater than benign pulmonary nodules; the sensitivity, specificity and accuracy were 97, 82 and $92 \%$, respectively. However, ${ }^{18} \mathrm{~F}-\mathrm{FDG}$ is known to have little uptake in malignancies with low metabolic activity, including bronchoalveolar cancer, carcinoid tumor and mucinous adenocarcinoma. Furthermore, certain noncancerous conditions may also demonstrate high metabolic rates (26). 


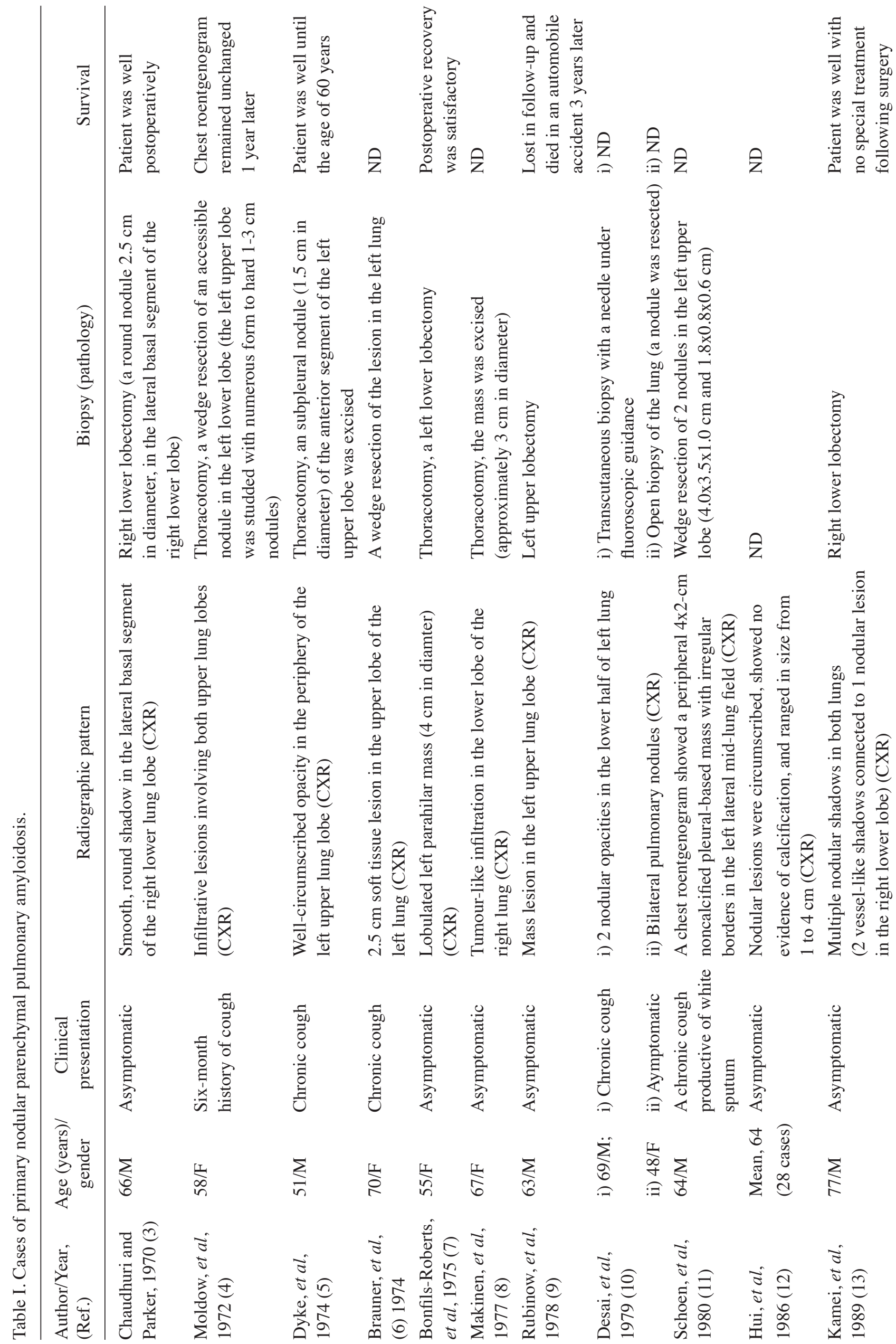




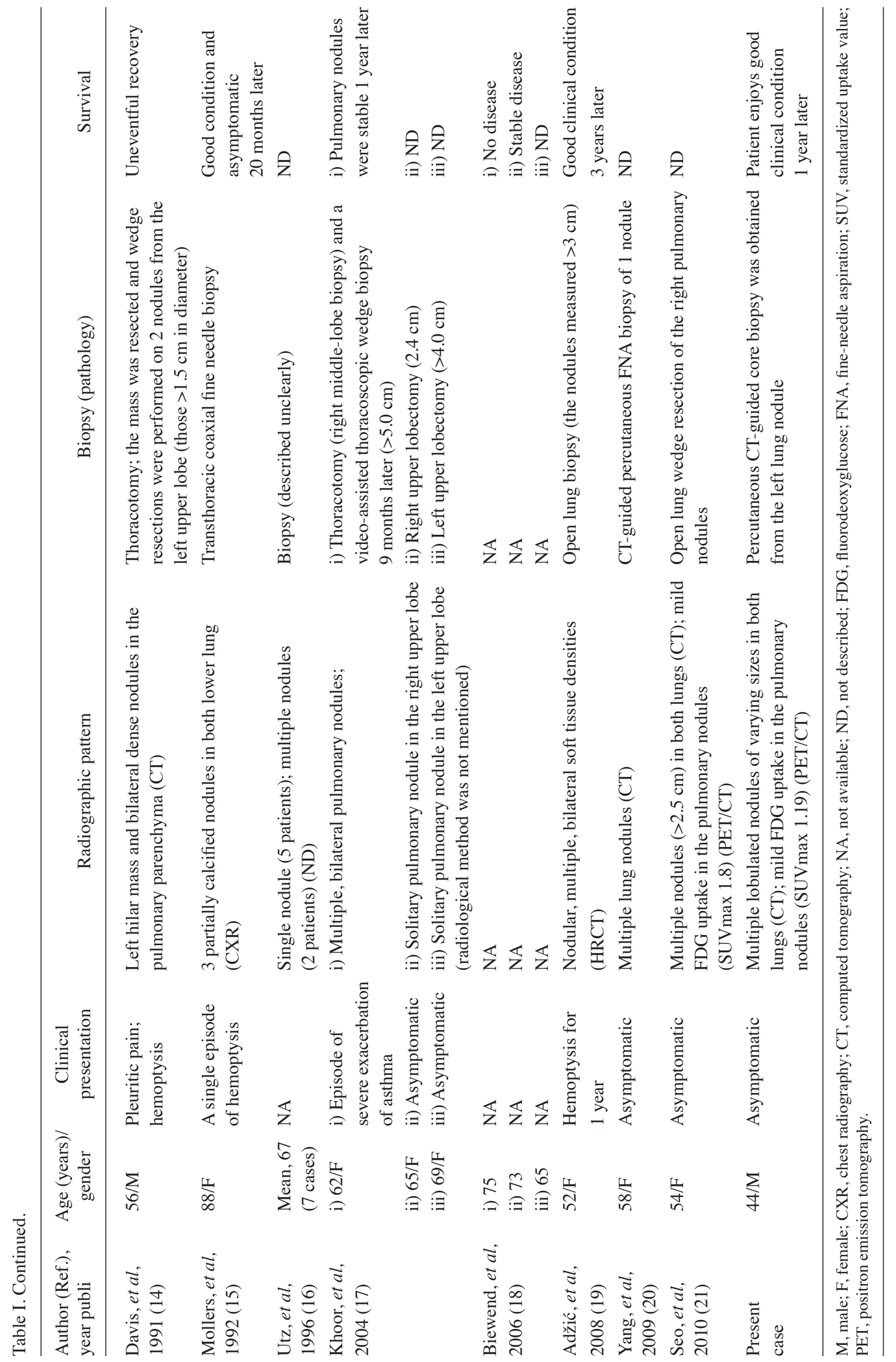


Increased ${ }^{18} \mathrm{~F}$-FDG activity has been demonstrated in cases of tuberculosis, sarcoidosis, fungal disease, interstitial lung disease, osteoarthritis, vascular thromboses, osteoporosis and rheumatoid nodules (27-29). The reason that noncancerous conditions uptake ${ }^{18} \mathrm{~F}-\mathrm{FDG}$ may be due to lesions with a high concentration of inflammatory cells, including neutrophils and activated macrophages, which increase glucose uptake $(30,31)$. Our case and the case reported by Seo et al (21) exhibited multiple lung nodules of pulmonary amyloidosis with moderate ${ }^{18}$ F-FDG uptake, and an SUVmax of 1.19 and 1.8, respectively. Our results suggest that positive results of ${ }^{18} \mathrm{~F}-\mathrm{FDG} \mathrm{PET} / \mathrm{CT}$ on pulmonary nodules should be interpreted with caution in differentiating pulmonary nodular amyloidosis from malignant lesions.

In conclusion, primary nodular parenchymal pulmonary amyloidosis is a relatively rare condition without classic clinical findings, laboratory tests and radiological results. Despite its rarity, primary nodular parenchymal pulmonary amyloidosis with a pattern of multiple nodules should be cautioned with the differential diagnosis of pulmonary metastases with high ${ }^{18} \mathrm{~F}-\mathrm{FDG}$ uptake on PET/CT.

\section{References}

1. Kim HY, Im JG, Song KS, Lee KS, Kim SJ, Kim JS, et al: Localized amyloidosis of the respiratory system: CT features. J Comput Assist Tomogr 23: 627-631, 1999.

2. Cordier JF, Loire R and Brune J: Amyloidosis of the lower respiratory tract. Clinical and pathologic features in a series of 21 patients. Chest 90: 827-831, 1986.

3. Chaudhuri MR and Parker DJ: A solitary amyloid nodule in the lung. Thorax 25: 382-386, 1970.

4. Moldow RE, Bearman S and Edelman MH: Pulmonary amyloidosis simulating tuberculosis. Am Rev Respir Dis 105: 114-117, 1972

5. Dyke PC, Demaray MJ, Delavan JW and Rasmussen RA: Pulmonary amyloidoma. Am J Clin Pathol 61: 301-305, 1974.

6. Brauner GJ, al-Bazzaz F and Mihm MC Jr: Acquired bullous disease of the skin and solitary amyloidoma of the lung. Am J Med 57: 978-986, 1974.

7. Bonfils-Roberts E, Marx AJ and Nealon TF: Primary amyloidosis of the respiratory tract. Ann Thorac Surg 19: 313-318, 1975.

8. Makinen J, Nickels J and Halttunen PE: Amyloid tumour of the lung. Report of a case and a short review of the literature. Acta Pathol Microbiol Scand A 85: 907-910, 1977.

9. Rubinow A, Celli BR, Cohen AS, Rigden BG and Brody JS: Localized amyloidosis of the lower respiratory tract. Am Rev Respir Dis 118: 603-611, 1978.

10. Desai RA, Mahajan VK, Benjamin S, Van Ordstrand HS and Cordasco EM: Pulmonary amyloidoma and hilar adenopathy. Rare manifestations of primary amyloidosis. Chest 76: 170-173, 1979.

11. Schoen FJ, Alexander RW, Hood CI and Dunn LJ: Nodular pulmonary amyloidosis. Description of a case with ultrastructure. Arch Pathol Lab Med 104: 66-69, 1980.
12. Hui AN, Koss MN, Hochholzer L and Wehunt WD: Amyloidosis presenting in the lower respiratory tract. Clinicopathologic, radiologic, immunohistochemical, and histochemical studies on 48 cases. Arch Pathol Lab Med 110: 212-218, 1986.

13. Kamei K, Kusumoto K and Suzuki T: Pulmonary amyloidosis with pulmonary arteriovenous fistula. Chest 96: 1435-1436, 1989.

14. Davis CJ, Butchart EG and Gibbs AR: Nodular pulmonary amyloidosis occurring in association with pulmonary lymphoma. Thorax 46: 217-218, 1991

15. Mollers MJ, van Schaik JP and van der Putte SC: Pulmonary amyloidoma. Histologic proof yielded by transthoracic coaxial fine needle biopsy. Chest 102: 1597-1598, 1992.

16. Utz JP, Swensen SJ and Gertz MA: Pulmonary amyloidosis. The Mayo Clinic experience from 1980 to 1993. Ann Intern Med 124: 407-413, 1996.

17. Khoor A, Myers JL, Tazelaar HD and Kurtin PJ: Amyloid-like pulmonary nodules, including localized light-chain deposition: clinicopathologic analysis of three cases. Am J Clin Pathol 121: 200-204, 2004

18. Biewend ML, Menke DM and Calamia KT: The spectrum of localized amyloidosis: a case series of 20 patients and review of the literature. Amyloid 13: 135-142, 2006.

19. Adžić TN, Stojšić JM, Radosavljević-Ašić GD and Bouros D: Multinodular pulmonary amyloidosis in primary Sjögren's syndrome. Eur J Intern Med 19: e97-e98, 2008.

20. Yang MC, Blutreich A and Das K: Nodular pulmonary amyloidosis with an unusual protein composition diagnosed by fine-needle aspiration biopsy: a case report. Diagn Cytopathol 37: 286-289, 2009.

21. Seo JH, Lee SW, Ahn BC and Lee J: Pulmonary amyloidosis mimicking multiple metastatic lesions on F-18 FDG PET/CT Lung Cancer 67: 376-379, 2010.

22. Gillmore JD and Hawkins PN: Amyloidosis and the respiratory tract. Thorax 54: 444-451, 1999.

23. Pepys MB: Amyloidosis. Annu Rev Med 57: 223-241, 2006.

24. Wahl RL: Targeting glucose transporters for tumor imaging: 'sweet' idea, 'sour' result. J Nucl Med 37: 1038-1041, 1996.

25. Duhaylongsod FG, Lowe VJ, Patz EF Jr, Vaughn AL, Coleman RE and Wolfe WG: Detection of primary and recurrent lung cancer by means of F-18 fluorodeoxyglucose positron emission tomography (FDG PET). J Thorac Cardiovasc Surg 110: 130-139, 1995.

26. Abouzied MM, Crawford ES and Nabi HA: 18F-FDG imaging: pitfalls and artifacts. J Nucl Med Technol 33: 145-155, 2005.

27. Ollenberger G, Knight S and Tauro A: False-positive FDG positron emission tomography in pulmonary amyloidosis. Clin Nucl Med 29: 657-658, 2004.

28. Shin L, Katz D and Yung E: Hypermetabolism on F-18 FDG PET of multiple pulmonary nodules res ulting from bronchiolitis obliterans organizing pneumonia. Clin Nucl Med 29: 654-656, 2004.

29. Hashefi M and Curiel R: Future and upcoming non-neoplastic applications of PET/CT imaging. Ann NY Acad Sci 1228: 167-174, 2011.

30. Brown RS, Leung JY, Fisher S, et al: Intratumoral distribution of tritiated-FDG in breast carcinoma: correlation between glut-1 expression and FDG uptake. J Nucl Med 37: 1042-1047, 1996.

31. Kubota R, Kubota K, Yamada S, Tada M, Ido T and Tamahashi N: Microautoradiographic study for the differentiation of intratumoral macrophages, granulation tissues and cancer cells by the dynamics of fluorine-18-fluorodeoxyglucose uptake. J Nucl Med 35: 104-112, 1994. 